\title{
Improving Science Learning Outcomes through the TPACK Approach in Class V Students of SDN 1 Besani
}

\section{Yeni Pratiwi}

SD Negeri 1 Besani

shakilasalsabila19@gmail.com

\section{Article History}

accepted $14 / 11 / 2020$

approved $21 / 11 / 2020$

published 26/11/2020

\begin{abstract}
The purpose of this study in particular was to improve science learning outcomes for fifth grade students of Elementary School 1 Besani, Leksono District, Wonosobo Regency in the first semester of the 2020/2021 school year, through the application of the TPACK approach. "This research was carried out for 3 cycles. By looking at the pre-cycle data, the data from the results of the first, second and third cycle assessments, there was an increase in learning outcomes and completeness in each cycle. The percentage of completeness of students which was only $43 \%$ in the initial conditions, increased to $71.4 \%$ in cycle I, $85,7 \%$ in cycle II and $92,8 \%$ in cycle III. From the increase in the value of these students it can be said that the learning outcomes of students have increased. So the authors can draw the conclusion that through the application of the TPACK approach can improve science learning outcomes Animal Classification Material by Type of Food in class V Elementary School 1 Besani, Leksono District, Wonosobo Regency in the first semester of the 2020/2021 school year.
\end{abstract}

Keywords: learning outcomes, application of the TPACK approach

\begin{abstract}
Abstrak
Tujuan penelitian ini secara khusus adalah untuk meningkatkan hasil belajar IPA bagi peserta didik kelas V Sekolah Dasar Negeri 1 Besani Kecamatan Leksono Kabupaten Wonosobo pada semester I tahun pelajaran 2020/2021, melalui penerapan pendekatan TPACK. Penelitian ini dilaksanakan selama 3 siklus.Dengan melihat data prasiklus, data hasil penilaian siklus I, II dan III terdapat peningkatan hasil belajar serta ketuntasan di setiap siklusnya, Persentase ketuntasan peserta didik yang hanya $43 \%$ pada kondisi awal, meningkat menjadi $71,4 \%$ pada siklus I, $85,7 \%$ pada siklus II dan $92,8 \%$ pada siklus III. Dari peningkatan nilai peserta didik tersebut dapat dikatakan bahwa hasil belajar IPA peserta didik mengalami peningkatan. Maka penulis dapat menarik kesimpulan bahwa melalui penerapan pendekatan TPACK dapat meningkatkan hasil belajar IPA Materi Penggolongan Hewan Berdasar Jenis Makanannya pada siswa kelas V Sekolah Dasar Negeri 1 Besani Kecamatan Leksono Kabupaten Wonosobo pada semester I tahun pelajaran 2020/2021.
\end{abstract}

Kata Kunci: hasil belajar, penerapan pendekatan TPACK

Social, Humanities, and Education Studies (SHEs): Conference Series https://jurnal.uns.ac.id/shes

p-ISSN 2620-9284

e-ISSN 2620-9292 


\section{PENDAHULUAN}

Memasuki revolusi industry 4.0 dunia pendidikan dituntut untuk mengkonstruksi pembelajaran yang melibatkan teknologi. Pendidikan 4.0 merupakan istilah yang digunakan oleh para ahli pendidikan untuk menggambarkan cara mengimplementasikan teknologi ke dalam pembelajaran. Pendidikan 4.0 menuntut guru menguasai teknologi untuk diintegrasikan dalam proses pembelajaran. Hal ini sesuai dengan peraturan menteri pendidikan nasional no 16 tahun 2007 yang menyatakan bahwa seorang guru harus mempunyai kompetensi di bidang teknologi informasi dan komunikasi.

Kemampuan guru dalam menguasai teknologi dalam pembelajaran dapat dilihat melalui TPaCK (Technological Pedagogical Content Knowledge) yang dimiliki guru. TPaCK merupakan kerangka teoritis untuk mengintegrasikan teknologi, pedagogik, dan materi pelajaran dalam pembelajaran. Kemampuan guru dalam menguasai teknologi dalam pembelajaran pada era industri 4.0 ini masih rendah. Hal ini juga terjadi dalam pembelajaran IPA Kelas V di SD Negeri 1 Besani Kecamatan Leksono Kabupaten Wonosobo Tahun ajaran 2020/2021. Guru masih menggunakan cara konvensional dalam melakukan kegiatan pembelajaran. Pembelajaran Tematik yang dilakukan guru selama ini kurang inovatif sehingga pembelajaran berlangsung monoton dan lebih didominasi guru.

Untuk mengatasi masalah tersebut maka guru berusaha mengubah kegiatan pembelajaran yang konvensional beralih dalam kegiatan pembelajaran dengan pengintegrasian teknologi (TPACK) yang sesuai dengan era industri 4.0, sehingga peserta didik lebih aktif dan pembelajaran berlangsung dengan menyenangkan. Upaya perbaikan yang dilakukan guru agar pembelajaran menjadi lebih menyenangkan adalah dengan pendekatan TPACK dalam pembelajaran. Melalui pendekatan TPACK ini peserta didik diharapkan akan lebih aktif dalam pembelajaran sehingga hasil belajar yang diperoleh semakin optimal.

Peneliti membatasi masalah yang akan diteliti hanya pada seberapa besar pendekatan TPACK dapat meningkatkan hasil belajar IPA materi penggolongan hewan berdasarkan jenis makanannya di kelas V SD Negeri 1 Besani Kecamatan Leksono Kabupaten Wonosobo pada semester I tahun ajaran 2020/2021.

Secara teoritis penelitian ini dapat menambah wawasan bagi penulis tentang penulisan karya ilmiah. Juga dapat menjadikan pengembangan pembelajaran IPA dalam penggunaan pendekatan TPACK bagi guru di SD Negeri 1 Besani khususnya dan dunia pendidikan pada umumnya. Juga dapat dijadikan pengalaman baru dalam strategi belajar mengajar.

Berdasarkan uraian di atas, penulis akan mencoba melakukan penelitian dengan tujuan meningkatkan hasil belajar IPA melalui pendekatan TPACK pada peserta didik di kelas V Sekolah Dasar Negeri 1 Besani Kecamatan Leksono Kabupaten Wonosobo semester I Tahun Pelajaran 2020/2021.

\section{METODE}

Penelitian ini merupakan penelitian tindakan kelas (PTK) kolaboratif yang dilaksanakan dalam tiga siklus, setiap siklus terdiri dari tahap perencanaan, pelaksanaan, observasi, dan refleksi. Subjek penelitian ini adalah peserta didik kelas $\mathrm{V}$ SD Negeri 1 Besani tahun pelajaran 2020/2021 yang berjumlah 14 peserta didik.

Pada penelitian ini ada dua jenis data, yaitu data kualitatif (hasil observasi setiap siklus pada lembar observasi) dan data kuantitatif nilai hasil pengerjaan instrumen evaluasi akhir siklus. Sumber data pada penelitian ini adalah peserta didik kelas V SD 
Negeri 1 Besani Kecamatan Leksono Kabupaten Wonosobo semester I tahun pelajaran 2020/2021, dan observer.

\section{HASIL DAN PEMBAHASAN}

Berdasarkan hasil penelitian dapat dikatakan bahwa rata - rata kelas dari nilai peserta didik dengan menggunakan pendekatan TPACK selalu meningkat. Hal tersebut dapat dilihat pada tabel berikut :

Tabel 1. Nilai Rata-rata kelas

Pada akhir siklus III indikator kinerja yang direncanakan sudah tercapai semua. Selain itu kekurangan-kekurangan yang terjadi pada siklus I dan II sudah dapat diatasi. Peningkatan kualitas proses pembelajaran tercermin melalui (a) Peserta didik terlibat aktif dalam pembelajaran (b) Peserta didik tidak malu bertanya bila mengalami kesulitan (c) Guru tidak mengalami kesulitan membangkitkan

\begin{tabular}{lllll}
\cline { 2 - 4 } $\begin{array}{llll}\text { keaktifan } \\
\text { didik dan }\end{array}$ & No & Keadaan & Nilai Rata-rata Kelas & peserta \\
\cline { 2 - 4 } tidak & 1 & Pra Siklus & 62 & (d) Guru \\
mengalami & 2 & Siklus I & 70 & kesulitan \\
dalam & 3 & Siklus II & 82 & \\
& 4 & Siklus III & 92 & \\
\cline { 2 - 3 } & 4 & 92 &
\end{tabular}

menerapkan pendekatan TPACK dalam pembelajaran materi penggolongan hewan berdasarkan jenis makanannya.

Tampilan data tersebut diatas terlihat adanya kenaikan pencapaian hasil belajar dari data prasiklus sampai data akhir siklus III yaitu pada pencapaian nilai maksimum, dan pencapaian ketuntasan klasikal. Hal ini menunjukkan bahwa penerapan pendekatan TPACK dapat meningkatkan hasil belajar IPA bagi peserta didik kelas V SD Negeri 1 Besani Kecamatan Leksono Kabupaten Wonosobo pada semester I tahun pelajaran 2020/2021.

\section{SIMPULAN}

Dengan melihat data prasiklus, data hasil penilaian siklus I,II dan III maka peningkatan hasil belajar dapat dilihat pada kenaikan ketuntasan di setiap siklusnya, nilai rata-rata kelas peserta didik yang hanya 62 pada kondisi awal, meningkat menjadi 70 pada siklus I , 82 pada siklus II serta menjadi 92 pada siklus III . Persentase ketuntasan pesrta didik juga mengalami peningkatan yang hanya $45 \%$ pada kondisi awal meningkat menjadi $71,4 \%$ pada siklus I, $85,7 \%$ pada siklus II dan mencapai $92,8 \%$ pada siklus III. Dari peningkatan nilai peserta didik tersebut dapat dikatakan bahwa hasil belajar IPA peserta didik mengalami peningkatan. Maka penulis dapat menarik kesimpulan bahwa melalui penerapan pendekatan TPACK dapat meningkatkan hasil belajar IPA bagi peserta didik kelas V SD Negeri 1 Besani Kecamatan Leksono Kabupaten Wonosobo pada semester I tahun pelajaran 2020/2021. 
DAFTAR PUSTAKA

Handayani, V. (2019). Metode E-Learning Sebagai Komponen TPACK Dalam Meningkatkan Hasil Belajar Peserta Didik Pada Materi Pokok Jaringan Hewan. http://repository.unpas.ac.id/46077/

Maulida, N. (2019). Pengaruh Pembelajaran Berbasis Technological Pedagogical Pedagogical And Conten Knowledge (TPACK) Dengan Blended Learning Terhadap Peningkatan Berkomunikasi Pada Materi Sistem Gerak. http://digilib.uinsgd.ac.id/29556/

Permendiknas. (2007). No. 16 Tahun 2007 tentang standar kualifikasi akademik dan kompetensi Guru, BSNP.

Rahman, B. (2015). Mempersiapkan guru professional (suatu pendekatan komprehensif). Bandar Lampung: FKIP Universitas Lampung.

Rosyid, A. (2016). Technological Pedagogical Content Knowledge sebuah kerangka pengetahuan bagi guru Indonesia di era MEA. https://jurnal.fkip.uns.ac.id/index.php/snip/article/view/8962

Sintawati, M., \& Indriani, F. (2019). Pentingnya Technological Pedagogical Content Knowledge (TPACK) Guru Di Era Revolusi Industri 4.0. http://digilib.uinsgd.ac.id/29556/

Sukaesih, S., Ridlo, S., \& Saptono, S. (2017). Analisis kemampuan technological pedagogical and content knowledge (TPACK) calon guru pada mata kuliah PP BioSNPS. 